\title{
Endoscopic endonasal atlantoaxial transarticular screw fixation technique: an anatomical feasibility and biomechanical study
}

\author{
George A. C. Mendes, MD, ${ }^{1}$ Curtis A. Dickman, MD, ${ }^{1}$ Nestor G. Rodriguez-Martinez, MD, ${ }^{2}$ \\ Samuel Kalb, MD, ${ }^{1}$ Neil R. Crawford, PhD, ${ }^{2}$ Volker K. H. Sonntag, MD, ${ }^{1}$ Mark C. Preul, MD, ${ }^{1}$ \\ and Andrew S. Little, MD'
}

'Division of Neurological Surgery, ${ }^{2}$ Spinal Biomechanics Research Laboratory, Barrow Neurological Institute, Saint Joseph's
Hospital and Medical Center, Phoenix, Arizona

OBJECT The primary disadvantage of the posterior cervical approach for atlantoaxial stabilization after odontoidectomy is that it is conducted as a second-stage procedure. The goal of the current study is to assess the surgical feasibility and biomechanical performance of an endoscopic endonasal surgical technique for $\mathrm{C} 1-2$ fixation that may eliminate the need for posterior fixation after odontoidectomy.

METHODS The first step of the study was to perform endoscopic endonasal anatomical dissections of the craniovertebral junction in 10 silicone-injected fixed cadaveric heads to identify relevant anatomical landmarks. The second step was to perform a quantitative analysis using customized software in 10 reconstructed adult cervical spine CT scans to identify the optimal screw entry point and trajectory. The third step was biomechanical flexibility testing of the construct and comparison with the posterior C1-2 transarticular fixation in 14 human cadaveric specimens.

RESULTS Adequate surgical exposure and identification of the key anatomical landmarks, such as C1-2 lateral masses, the $\mathrm{C}-1$ anterior arch, and the odontoid process, were provided by the endonasal endoscopic approach in all specimens. Radiological analysis of anatomical detail suggested that the optimal screw entry point was on the anterior aspect of the C-1 lateral mass near the midpoint, and the screw trajectory was inferiorly and slightly laterally directed. The custommade angled instrumentation was crucial for screw placement. Biomechanical analysis suggested that anterior $\mathrm{C} 1-2$ fixation compared favorably to posterior fixation by limiting flexion-extension, axial rotation, and lateral bending $(p>0.3)$.

CONCLUSIONS This is the first study that demonstrates the feasibility of an endoscopic endonasal technique for C1-2 fusion. This novel technique may have clinical utility by eliminating the need for a second-stage posterior fixation operation in certain patients undergoing odontoidectomy.

http://thejns.org/doi/abs/10.3171/2014.10.SPINE14374

KEY WORDS craniovertebral junction; endoscopy; odontoidectomy; atlantoaxial fusion; biomechanics; cervical

$\mathrm{T}$ HE management of anterior compression at the craniovertebral junction $(\mathrm{CVJ})$ is particularly challenging due to the structure's narrow and deep operative field and its anatomical association with critical neurovascular structures. The CVJ is considered the most complex and dynamic segment of the spine, because most of the axial rotation and a substantial amount of flexion, extension, and lateral bending occur at this segment. ${ }^{4,12}$ Pathological entities that occur in this region include congenital anomalies, rheumatoid arthritis, tumors, infections, and trauma.
These conditions can be associated with ventral brainstem and spinal cord compression and atlantoaxial instability. $2,3,24,29,31,32$ In cases of nonreducible ventral compression, the transoral route is the most accepted approach..$^{9,11,13}$ More recently, others have demonstrated the feasibility of endoscopic endonasal odontoidectomy.,18 Regardless of the surgical approach, atlantoaxial instability requiring surgical fixation occurs in approximately $70 \%$ of patients after odontoidectomy. ${ }^{10,12}$

The posterior cervical approach is the most accepted

ABBREVIATIONS AP = anteroposterior; $\mathrm{CVJ}=$ craniovertebral junction; $\mathrm{ROM}=$ range of motion; $\mathrm{VA}=$ vertebral artery. SUBMITTED April 10, 2014. ACCEPTED October 7, 2014.

INCLUDE WHEN CITING Published online February 13, 2015; DOI: 10.3171/2014.10.SPINE14374.

DISCLOSURE The authors report that NuVasive provided the manual angled instruments for screw placement and that an employee of Medtronic provided technical guidance for using the StealthStation navigation system. The research was supported in part by the Newsome Family Endowment. The authors have no personal financial or institutional interest in any of the materials or devices described in this article. 
approach to achieve atlantoaxial stabilization after odontoidectomy. ${ }^{17}$ The posterior atlantoaxial transarticular fusion is a well-established procedure, which provides immediate joint stabilization, reaching $100 \%$ of fusion rates in some series..$^{20}$ Nevertheless, posterior fixation has some disadvantages in this setting, such as the need for a second procedure in addition to the odontoidectomy, additional operative time, need for repositioning a patient with an unstable cervical spine, and the inherent risks of any posterior spine surgery such as wound infection and vertebral artery (VA) injury. ${ }^{17}$ Therefore, an alternative surgical method that abrogates the second-stage procedure and provides immediate stabilization of the C1-2 joint is a conceptually appealing idea. In this study, we investigate performing C1-2 transarticular fixation from an endonasal approach and study its biomechanical performance in comparison with the posterior $\mathrm{C} 1-2$ transarticular technique.

\section{Methods}

This study comprised 3 components. The first component examined the anatomical landmarks and feasibility of anterior atlantoaxial endonasal instrumentation. The second component included a radiological evaluation of anatomical detail of the CVJ to determine optimal screw entry point and trajectory. The third component involved the biomechanical assessment of the construct in a cadaveric spine model.

\section{Surgical Procedure}

Cadaveric dissections were performed in 10 cadaveric, silicone-injected, formalin-fixed specimens (20 sides), which included an intact head and upper cervical spine. All of the heads were scanned using high-resolution fine-cut CT (64-slice, 1-mm slice spacing; LightSpeed Plus, General Electric) and the images were registered on a StealthStation Treatment Guidance System workstation (Treon-Medtronic Surgical Navigation Technologies). The dissections were assisted by C-arm fluoroscopy (OEC 9800 Plus, GE Healthcare) during the screw placement step.

The mean age of the specimens was 74.2 years (range 47-92 years). There were 3 female and 7 male specimens. Before dissection, the heads were rigidly fixed in a Mayfield headholder and they were positioned to simulate the orientation used in an operating room. The procedures were performed using standard rigid endoscopes (4 $\mathrm{mm}$ in diameter and $18 \mathrm{~cm}$ in length) with a $0^{\circ}$ lens connected to a high-definition camera control unit and a 26-inch high-definition flat screen monitor (Karl Storz Endoscopy-America). All digital images were documented using an independent audiovisual system (AIDA DVD-M system, Karl Storz Endoscopy-America). Operative procedures were performed by 2 neurosurgeons using a bimanual technique.

The middle turbinate was resected on the right and outfractured on the left. A posterior septectomy and bilateral sphenoidotomies were performed. The wide sphenoidectomy was performed to the level of the clivus to visualize relevant anatomical landmarks. A U-shaped myomucosal flap with a caudal base was raised on the nasopharyngeal mucosa and reflected caudally. The incision was made over the nasopharynx, which was transversely incised at the level of the floor of the sphenoid sinus and longitudinally incised parallel to the eustachian tube apertures. Thereafter, the longus capitis and colli muscles were detached at the level of the basipharyngeal fascia and downward reflected along with the nasopharyngeal mucosa in a single layer, revealing the lower clivus, foramen magnum, anterior atlantooccipital membrane, anterior arch of C-1, and the body of C-2. Following the subperiosteal dissection of the paraspinal muscles, the anterior arch of the atlas and odontoid process were drilled out using a highspeed drill (Anspach Effort, Inc.). The transverse ligament and tectorial membrane were identified and kept intact. Subsequently, the C1-2 joint was opened up with a knife and denuded of the synovial cartilage. The C-1 inferior facet and C-2 superior facet were both decorticated using a combination of delicate curette and drill, and bone graft pieces were stuffed within the articular cavity. A customized $45^{\circ}$ angled manual drill (NuVasive) was used to make the pilot hole. Navigation coordinates were consistently assessed during the screw placement step.

\section{Radiological Analysis of Anatomical Detail}

We used custom image analysis software (Image Tool, Department of Dental Diagnostic Science, University of Texas Health Science Center, San Antonio) that allows for reslicing of CT volumes through selected angles to examine 10 adult cervical spines ( 7 males and 3 females, mean age 64.2 years [range 36-86 years]) from our archive. CT scans (64-slice, 1-mm slice spacing; General Electric LightSpeed Plus, General Electric) had been obtained in these individuals for other purposes and were used in this study for assessing the optimal trajectory. Images in patients with CVJ disease or fractures, rotation distortion, or unacceptable anatomy for transarticular screw placement were excluded. The cross-referencing system allows matching axial, sagittal, and coronal planes; therefore, the entry point and angles of screw orientation could be quantified. A marker was placed at the level of the middle of the anterior tubercle of the atlas. Next, the image was scrolled up to the level of the lateral mass, keeping the marked position visible. The optimal vertical position of the entry point was determined at the level of the mark on the anterior surface of the lateral mass. Multiple screw trajectories with different axial and vertical angulations were simulated to determine the optimal trajectory. As published elsewhere, ${ }^{21}$ a screw length able to achieve $\geq 10$ $\mathrm{mm}$ of bony purchase in the C-2 pedicle without cortical bony breaks was considered adequate.

\section{Biomechanical Assessment}

Biomechanical pure moment tests were performed in 14 unembalmed human cadaveric specimens (skull base with the first and second cervical vertebrae attached). The specimens were divided into 2 groups. Group 1, the anterior transarticular screw group, comprised 3 male and 4 female cadavers (mean age 49.71 years, range 38-59 years). Group 2, the posterior transarticular screw group, comprised 5 male and 2 female cadavers (mean age 53.42 years, range 33-62 years). None of the specimens had radiographic or visible flaws, or osteoporosis as determined by dual-energy x-ray absorptiometry scans. 
Each specimen first underwent flexibility testing in its intact state to acquire a baseline for range of motion (ROM) and to serve as its own control. After intact testing, the anterior $\mathrm{C}-1$ arch and odontoid process were resected using a high-speed drill to simulate atlantoaxial instability. The cruciate ligament and tectorial membrane were preserved, and screws were inserted under fluoroscopic guidance. In Group 1, a self-cutting 4.0-mm-diameter and 32-mm-long cortical screw was anteriorly placed in both sides by using entry points, and a trajectory was established according to the radiological analysis. Screws were advanced toward the pars interarticularis of C-2. In Group 2 , cannulated screws $(4 \mathrm{~mm}$ in diameter and $32 \mathrm{~mm}$ in length) were placed over the wires, according to standard techniques. ${ }^{23}$ Screw placement was confirmed using anteroposterior (AP) and lateral fluoroscopy and by direct inspection of the specimens.

\section{Biomechanical Testing Protocol}

The caudal surface of the axis (C-2 vertebra) of each specimen was reinforced using small household screws and potted in a block of fast-curing resin (Smooth-Cast 300Q, Smooth-On, Inc.) in a cylindrical metal fixture for load application. The skull base was fixed to a wooden board using household screws and to the base of the testing apparatus as previously described. ${ }^{28}$ An angle vise was oriented so that the gravitational preload was directed axially along the spine in its neutral posture. To track displacement of the occiput, $\mathrm{C}-1$, and $\mathrm{C}-2$, infrared-emitting diodes were attached to the ends of 3 stainless steel surgical guidewires rigidly inserted into each vertebral body (9 markers total). Marker positions were tracked three-dimensionally using stereophotogrammetry (Optotrak 3020, Northern Digital, Inc.) as previously described..$^{10}$ Marker positional data were converted to occiput-C1 and $\mathrm{Cl}-2$ angular motions by establishing local coordinate systems at each level ${ }^{6}$ and quantifying tilt-twist angles. ${ }^{8}$ Fourteen specimens were loaded to induce flexion and extension (flexion-extension), axial rotation (left and right), and lateral bending (left and right) using a system of cables and pulleys in conjunction with a uniaxial servohydraulic test frame (858 Mini Bionix, MTS Systems) as described elsewhere. ${ }^{5,34}$ For each direction of loading, 3 preconditioning cycles at $1.5 \mathrm{Nm}$ were applied for 60 seconds each before data were collected. During the data collection cycle, nondestructive pure moments were applied in 0.25 -Nm increments to a maximum of $1.5 \mathrm{Nm}$ to induce physiological ROMs as has been previously performed in studying the CVJ. ${ }^{5,34}$ Each increment was held for 45 seconds to provide the quasistatic limiting response. ${ }^{27}$ Range of motion was normalized before statistical comparisons to mitigate effects related to variability among specimens. For normalization, these variables were divided by the ROM in the intact condition to provide a dimensionless ratio relative to the intact state.

\section{Data Analysis}

For each direction of loading, 1-tailed paired Student t-tests were used to determine whether each step of the procedure significantly increased motion compared with the intact baseline measurements. Because these $p$ values were intended only to assess whether a sizable increase in a parameter had occurred and not to establish an overall superiority of one condition relative to others, the level of significance was not adjusted for multiple comparisons. A $\mathrm{p}$ value $<0.05$ was considered statistically significant.

\section{Results}

\section{Surgical Exposure}

Exposure was achieved from the planum sphenoid to the body of $\mathrm{C}-2$ in all specimens. With gentle lateral displacement of the tubal elevations, the lateral masses of $\mathrm{C}-1$ and C-2 were visible (Fig. 1). Lateral extension of the approach was limited by both tubal elevations and mucous folds of the nasopharynx. The caudal extension of the approach was constrained by the posterior edge of the hard palate, which was consistently located near the level of the anterior arch of the atlas. Adequate visualization was achieved in the inferior part of the operative field with a straight lens by applying gentle upward pressure on the nasal cartilage. The nasal cartilage limited the endoscope during the downward angulation.

\section{Radiological Evaluation of Anatomical Detail}

The entry point was established $6.0 \pm 1.0 \mathrm{~mm}$ lateral to the medial border of the C-1 lateral mass, which positioned the point near the middle of the anterior surface of the C-1 lateral mass and provided the most anterior-posterior trajectory toward the C-2 pars interarticularis (Figs. $2-4)$. The optimal vertical position for the entry point was determined to be $9.0 \pm 1.9 \mathrm{~mm}$ superior to the $\mathrm{C} 1-2$ joint, which is in the safe zone for screw placement $2.5 \mathrm{~mm}$
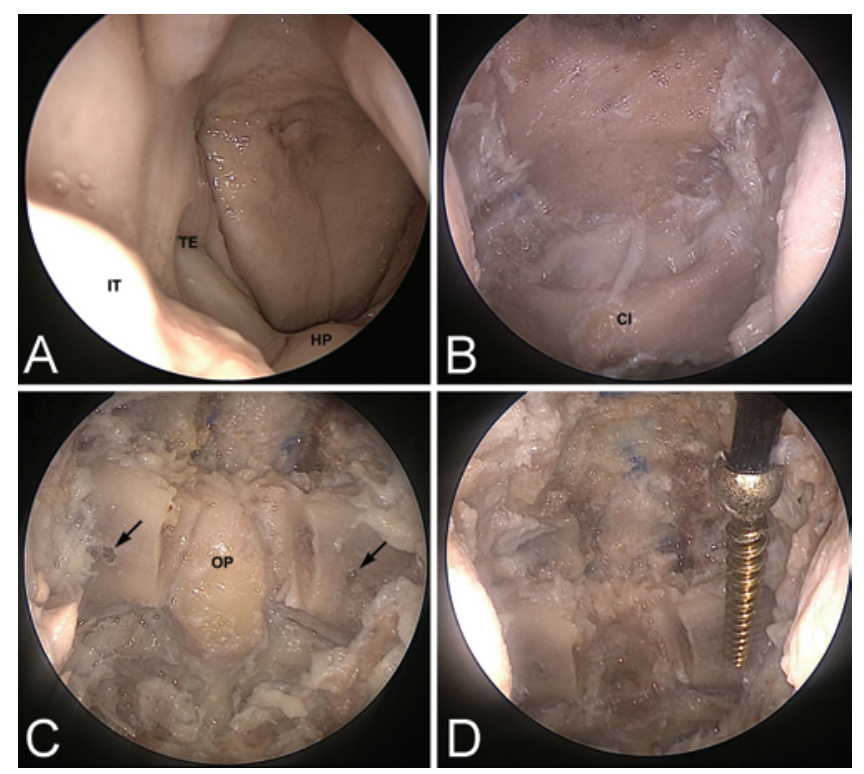

FIG. 1. Photographs of the cadaveric dissection of the craniovertebral junction. A: View from the right nostril of the nasopharynx, tubal elevations (TE), hard palate (HP), and inferior turbinate (IT). B: Exposure of the $\mathrm{C}-1$ anterior arch (C1) following bilateral sphenoidotomy and raising the mucosal flap. C: The $\mathrm{C}-1$ arch has been removed, exposing the odontoid process (OP). Pilot holes for the screws have been drilled in the lateral mass of $\mathrm{C}-1$ (arrows). The $\mathrm{C} 1-2$ articulation is noted. D: Placement of transarticular screw using an angled driver following odontoidectomy. 

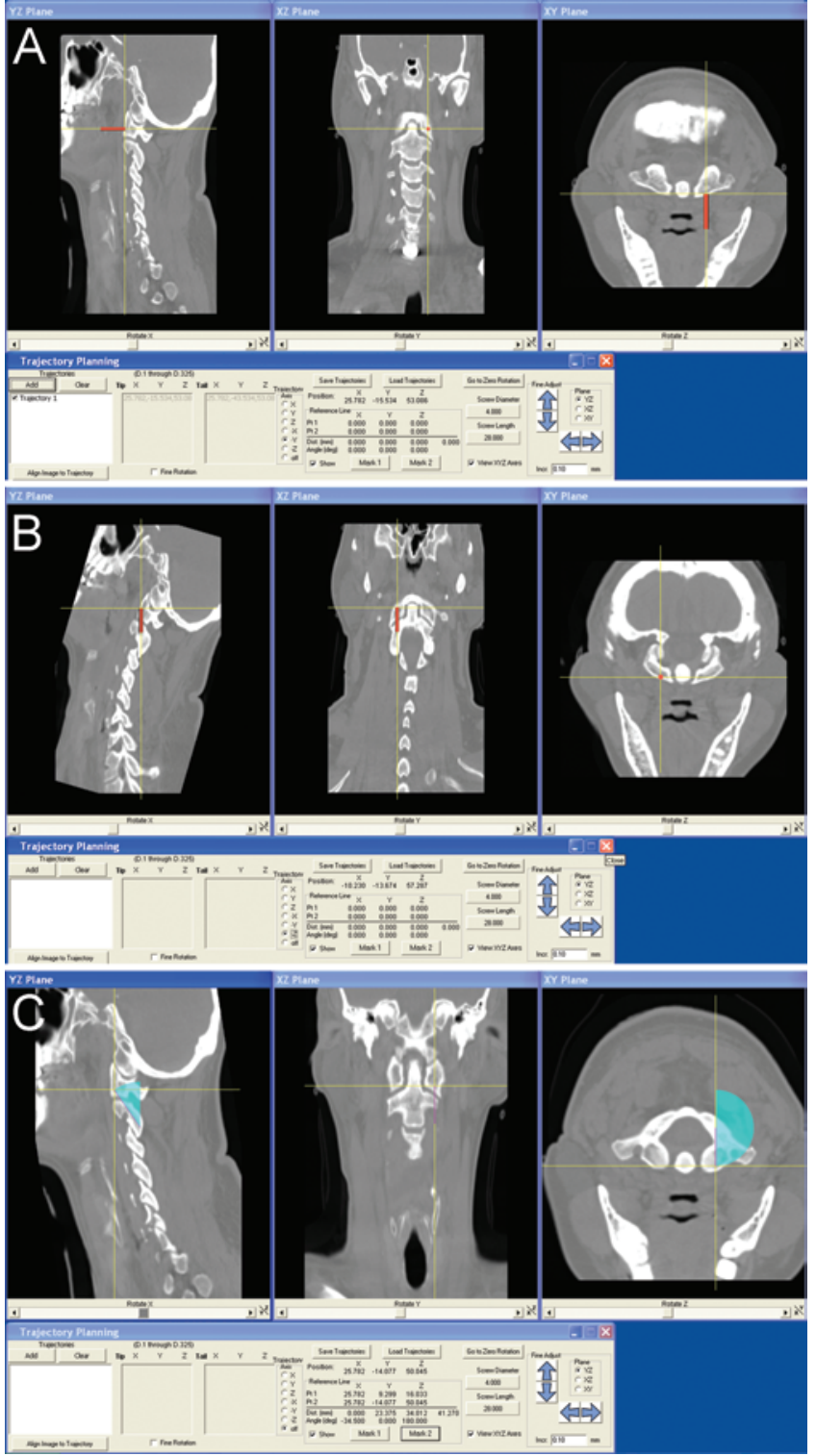

FIG. 2. Customized software used to estimate the optimal entry point and trajectory. The cross-referencing system reslices the $\mathrm{CT}$ volumes through selected angles and positions and renders the axial, sagittal, and coronal planes during simulated screw placement. A: Determination of the optimal entry point. B: Simulation of the optimal screw trajectory. C: Determination of the vertical and axial angles for screw placement.

away from the cranial and caudal cortex of the atlas and axis, as defined by Kandziora et al. ${ }^{17}$ This point also permits more than $0.5 \mathrm{~mm}$ of bone around the screw, which is associated with an optimal bony purchase. ${ }^{26}$ The mean optimal axial angulation was $9^{\circ}$ lateral (range $3.9^{\circ}-13^{\circ}$ ) and $38^{\circ}$ inferior $\left(\right.$ range $31^{\circ}-43^{\circ}$ ).

\section{C1-2 Transarticular Screw Placement}

The information we gained from the radiological analysis was applied to placing endoscopic endonasal C1-2 screws in a cadaveric craniospinal model in siliconeinjected specimens (Figs. 3 and 4). Image guidance was
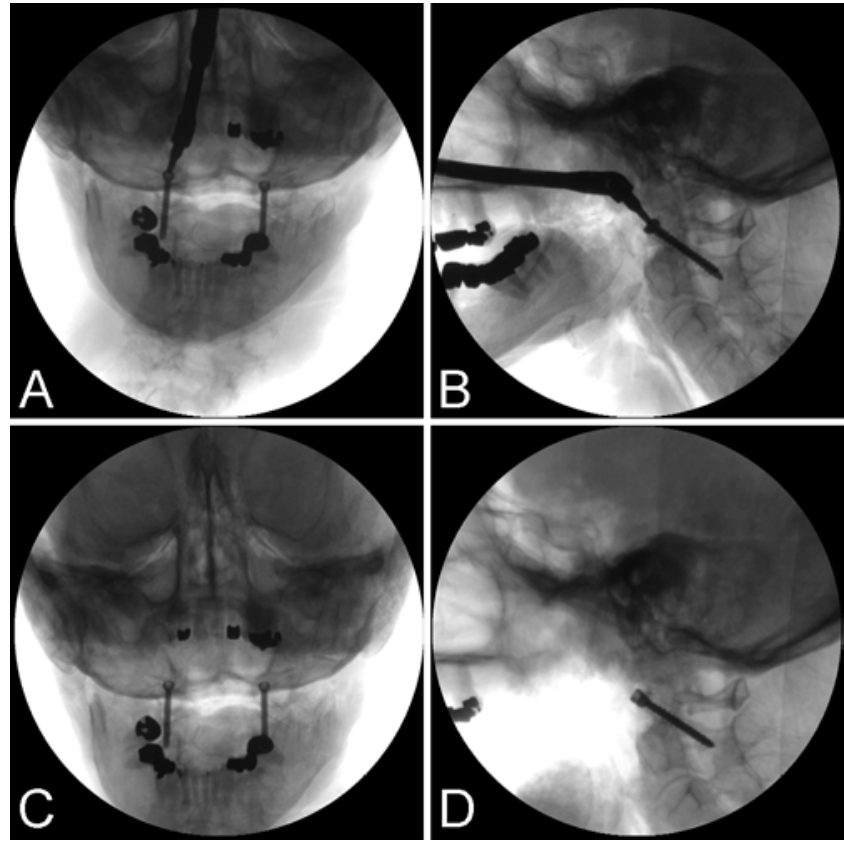

FIG. 3. Radiographs showing $C 1-2$ endoscopic transnasal transarticular screw placement. A and B: AP (A) and lateral (B) projections during the intraoperative screw placement. $C$ and D: Final AP $(C)$ and lateral (D) images obtained after screw placement demonstrating capture of the $\mathrm{C} 1-2$ joint. The optimal trajectory is $38^{\circ}$ caudally directed toward the $\mathrm{C}-2$ pars interarticularis in the vertical plane and $9^{\circ}$ lateral to capture the joint.

used to confirm the screw entry point. The customized angled instruments were indispensable for placing the screws. A $45^{\circ}$ manual drill and a $45^{\circ}$ screwdriver were developed for the proposed technique. A screw size of 32 $\mathrm{mm}$ in length and $4 \mathrm{~mm}$ in diameter was used because it was the longest screw that could be manipulated in the nasal cavity. Longer screws were not able to reach the optimal vertical angulation and did not fit in the nasal cavity during the dissections, whereas shorter screws did not reach more than $10 \mathrm{~mm}$ of bony purchase in C-2. The eustachian tubes were used as key landmarks because the screw entry points were placed behind and lateral to the tubal elevations. The preparation of the entry points was performed using regular dissectors, and the pilot hole was completed with a $45^{\circ}$ angled drill under fluoroscopic guidance. We used a 30-mm drill tip, which was sufficient for drilling across the joint articular surface, purchasing both cortical margins in all specimens. Screw placement was confirmed using AP and lateral fluoroscopy. CT scans were not used as a confirmatory study.

\section{Biomechanical Analysis}

Angular ROM was evaluated in the intact state and after placement of anterior and posterior C1-2 transarticular screws following odontoidectomy (Tables 1 and 2; Fig. 5). Both posterior and anterior configurations successfully fixated the C1-2 articulation following odontoidectomy. Compared with that in the intact condition, significant diminution in ROM was noted during all directions of loading ( $\mathrm{p}<0.03$ ), especially during axial rotation (less 


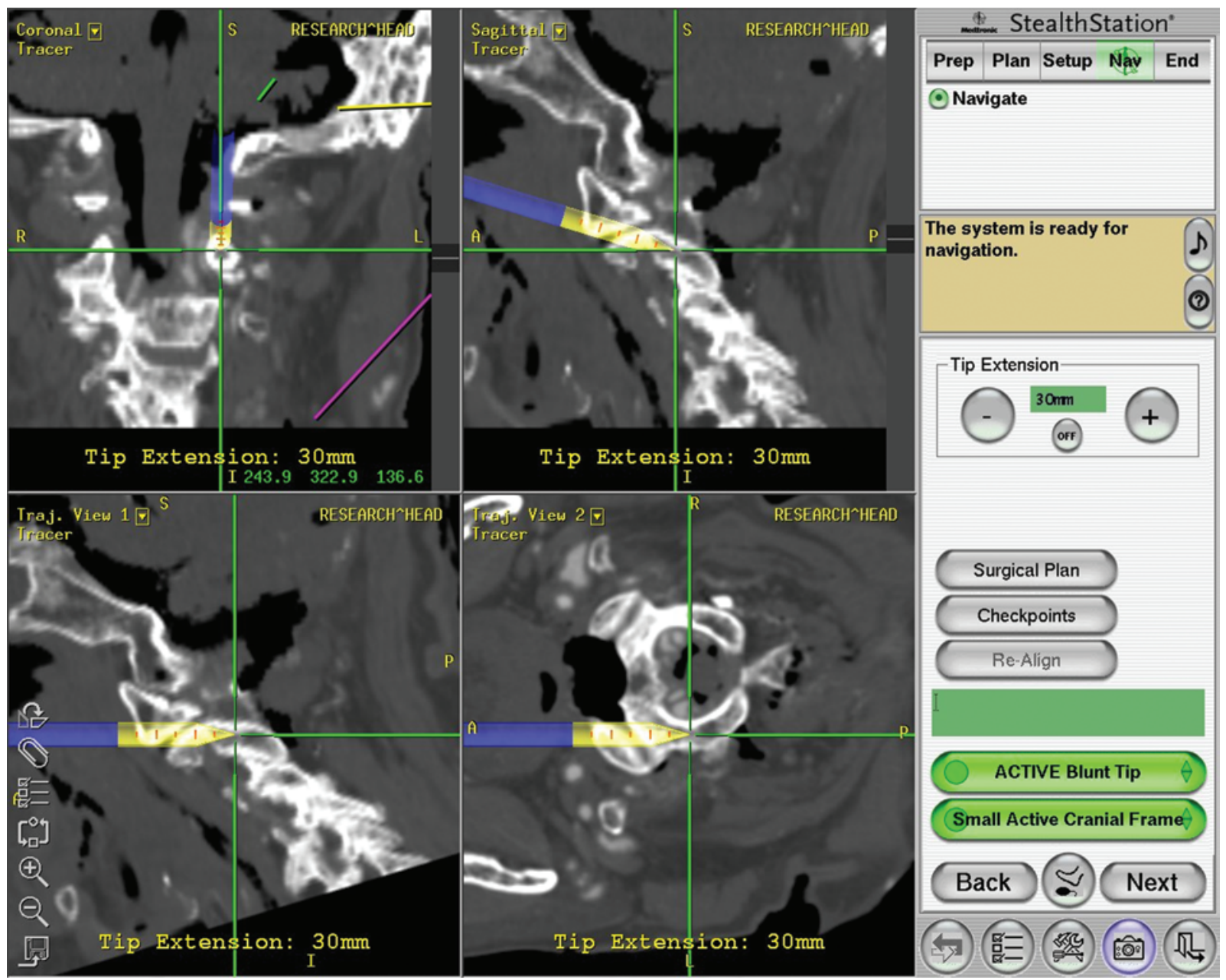

FIG. 4. Image guidance snapshots demonstrating the trajectory of transarticular screws in a cadaveric specimen.

than $4 \%$ of intact; Table 2). Comparing normalized ROM of anterior and posterior fixation techniques revealed no significant differences between techniques ( $p>0.28$; Table 2).

\section{Discussion}

The endoscopic endonasal approach for the $\mathrm{CVJ}$ region was first proposed by Alfieri et al. ${ }^{1}$ in a cadaveric study. Kassam et al. ${ }^{18}$ demonstrated the clinical applicability in a case of symptomatic rheumatoid pannus. Subsequently, $\mathrm{Wu}$ et al. ${ }^{37}$ reported 3 successful cases in which the authors described using a Hardy bivalve speculum for retraction and a linear incision rather than a mucosal flap in the nasopharynx. Some proposed advantages of the endonasal approach compared with the traditional transoral microscopic approach include better surgical visualization in deep corridors, better rostral access to the CVJ region, and shorter distance to the odontoid tip. Similarly, certain complications associated with the transoral route may be prevented with the endonasal corridor, such as tongue and nasopharyngeal swelling, dental injury, tracheostomy, and prolonged intubation. . $^{31,37,40}$

Biomechanical studies demonstrate that after odontoid- ectomy significant instability is noted in both the neutral zone and ROM. We have demonstrated previously that odontoidectomy destabilizes the spine significantly more than odontoid traumatic fractures or transverse-alar-apical ligament disruption, especially during flexion and extension. ${ }^{7}$ The preferred options for $\mathrm{C} 1-2$ fixation use a posterior approach. Different techniques have been described, including C1-2 wiring, posterior atlantoaxial transarticular fusion, $\mathrm{C} 1-2$ fusion with polyaxial screw and rod fixa-

TABLE 1. Mean angular range of motion (in degrees) at the C1-2 joint in intact and instrumented specimens following odontoidectomy

\begin{tabular}{crcr}
\hline Variable & Flexion-Extension & Lateral Bending & Axial Rotation \\
\hline ATAS & & & \\
\hline Intact & $16.9 \pm 2.6$ & $9.5 \pm 4.8$ & $74.7 \pm 5.9$ \\
\hline Fixated & $7.1 \pm 6.0$ & $3.2 \pm 1.5$ & $2.8 \pm 2.1$ \\
\hline PTAS & & & \\
\hline Intact & $19.4 \pm 6.0$ & $10.9 \pm 8.8$ & $76.9 \pm 5.3$ \\
\hline Fixated & $7.0 \pm 6.0$ & $3.0 \pm 2.1$ & $2.9 \pm 2.1$ \\
\hline
\end{tabular}

ATAS $=$ anterior transarticular screw; PTAS $=$ posterior transarticular screw. 
TABLE 2. Summary of $p$ values obtained in biomechanical testing

\begin{tabular}{lccc}
\hline \multicolumn{1}{c}{ Variable } & ATAS vs Intact & PTAS vs Intact & ATAS vs PTAS \\
\hline Flexion & 0.003 & $<0.0001$ & 0.283 \\
\hline Extension & 0.002 & 0.001 & 0.915 \\
\hline Lateral bending & 0.006 & 0.025 & 0.915 \\
\hline Axial rotation & $<0.0001$ & $<0.0001$ & 0.888 \\
\hline
\end{tabular}

tion, and occipitocervical instrumentation. ${ }^{23,32}$ Several in vitro studies have demonstrated that a transarticular atlantoaxial construct has superior biomechanical performance compared with other fixation methods. . $4,16,20,25,35,36$

In the setting of odontoidectomy, there are certain drawbacks to performing a posterior cervical stabilizing procedure. These include the requirement to reposition the patient during a period of spinal laxity, which could result in spinal cord injury, additional operative time, and wound infection. The posterior technique is also limited in patients with cervical hyperlordosis, thoracic kyphosis, and obesity. ${ }^{22}$

Harms et al..$^{15}$ first introduced the concept of an anterior fusion of $\mathrm{Cl}-2$ after resecting the odontoid process. The authors used a butterfly-shaped plate combined with 4 cancellous screws: 2 in the lateral masses and 2 in the axis body $^{39}$ via a standard transoral approach. Subsequently, others have made modifications to this technique. ${ }^{17}$ Instant stabilization of the spine, excellent fusion rates, and low incidence of postoperative infection or healing complications have been associated with this technique. ${ }^{16,17,19,30,39}$ Kandziora et al. ${ }^{17}$ demonstrated in an anatomical study that the safe zone for screw placement on the anterior surface of the C-1 lateral mass is encompassed in a bilateral trapezoid placed between 10.2 and $23.5 \mathrm{~mm}$ lateral to the sagittal plane. ${ }^{17}$

Our study demonstrates that a C1-2 transarticular fixation is feasible via an endoscopic endonasal approach to the $\mathrm{CVJ}$ and describes the relevant anatomical landmarks (Fig. 6). Biomechanical testing suggested that the anterior transarticular screw technique successfully fixated the C1-2 joint and was comparable to the posterior transarticular screw technique. After odontoidectomy, both screw configurations demonstrated significant reduction of motion in all directions of loading $(p<0.03)$. One limitation of the study is that screw placement was confirmed with fluoroscopy and direct inspection of the specimens rather than with CT scan. There are several important technical nuances that should be considered. First, a wide sphenoidectomy significantly increased the operative field and was important to allow a proper trajectory of the screw. Second, a modified, 1-layer, inverted U-shaped flap provided the necessary medial-lateral exposure. The flap can be sutured or simply reapposed with absorbable packing. An alternative is to make separate incisions in the fossa of Rosenmüller directly over each of the C-1 lateral masses. These incisions can then be left to heal by second intention. Third, multiple custom instruments including an angled manual drill and screwdriver were necessary. The use of intraoperative image guidance to identify screw entry points combined with fluoroscopy during screw place-

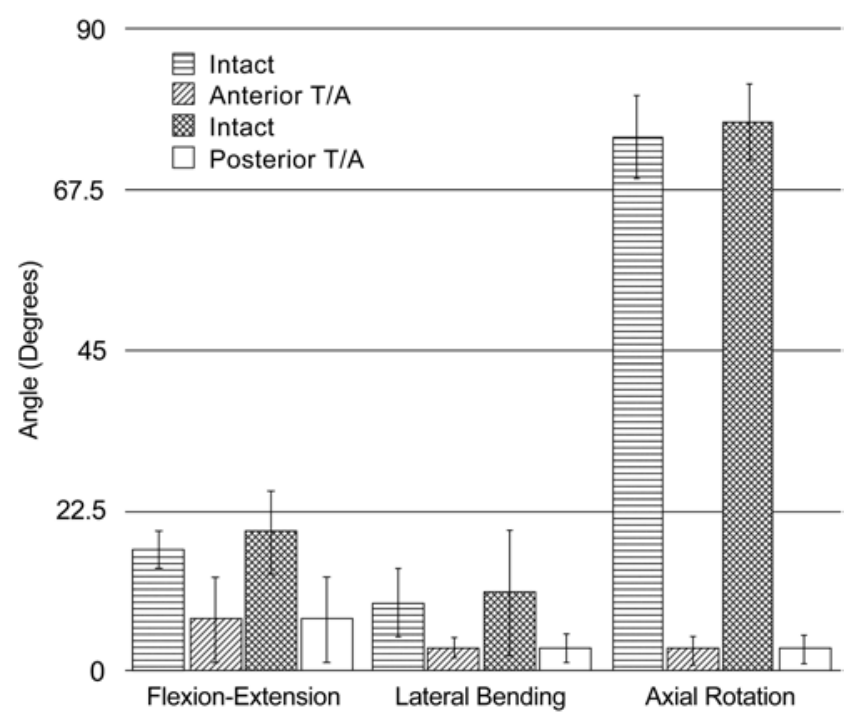

FIG. 5. Biomechanical cadaveric analysis of mean C1-2 angular ranges of motion (degrees) for anterior and posterior transarticular fixation techniques in flexion, extension, lateral bending, and axial rotation. $\mathrm{T} / \mathrm{A}=$ transarticular screw.

ment was helpful. As with any new surgical technique, we expect a learning curve for its successful application. In addition to mastering a basic endoscopic endonasal technique by performing pituitary surgery or repairing CSF leaks, we recommend performing cadaveric screw placement prior to attempting the technique in patients.

\section{Clinical Applicability, Limitations, and Advantages}

The endonasal transarticular technique could be considered in cases in which supplemental transarticular fixation is required after endonasal odontoidectomy. The endonasal transarticular technique uses a natural orifice and provides a straightforward route to the surgical target at the time of odontoidectomy. One potential advantage includes reduced operative time because of the elimination of the need for a second-stage posterior approach. Furthermore, this technique may benefit patients with contraindications for posterior cervical fusion, including cervical hyperlordosis, thoracic hyperkyphosis, and excessive obesity. Potential disadvantages include unfavorable pars interarticularis anatomy in some patients. For example, patients with extensive destruction of the pars, a congenitally narrow pars, or high-riding vertebral arteries may not be candidates for this procedure. The other potential disadvantage is the bony surface available for fusion. In the anterior transarticular screw technique described here, the bone graft is placed in the $\mathrm{C} 1-2$ joint. In the posterior transarticular screw technique, not only can bone graft can be placed in the joint, but it can also be wired to the $\mathrm{C}-1$ ring and $\mathrm{C}-2$ spinous process or placed over the lateral masses.

One can conceive of the risks of using this technique. The medial violation of the C-1 lateral mass and/or C-2 isthmus could lead to spinal cord injury or CSF leak. That risk could be mitigated by ensuring that the screw entry point is sufficiently lateral on the lateral mass. With respect to infection risk, even though this concern is warranted for 


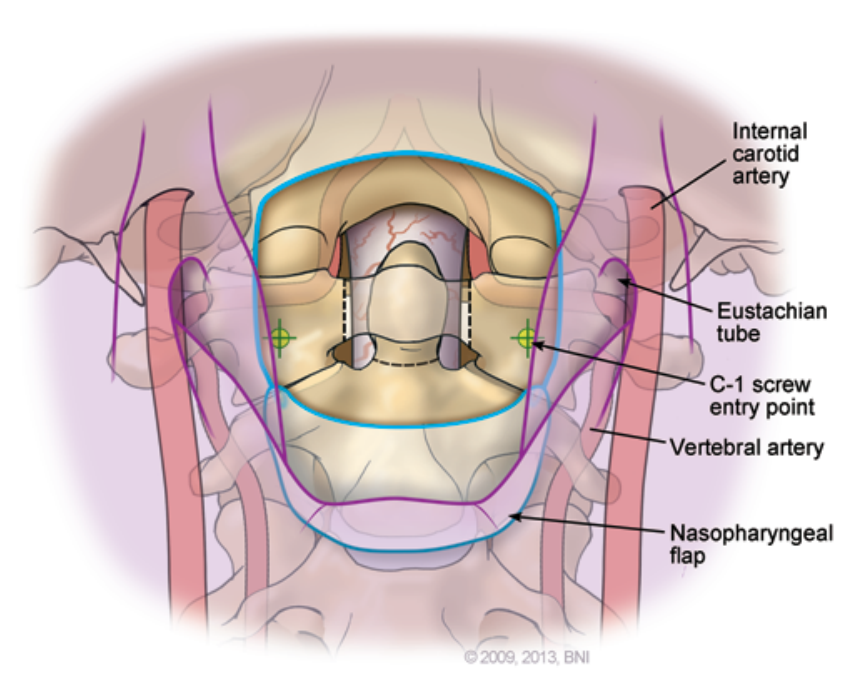

FIG. 6. Schematic illustration demonstrating the key anatomical relationships for the screw placement after elevating the nasopharyngeal flap. The nasopharyngeal mucosa, longus capitis, and longus colli muscles were reflected downward. The entry points are prepared on the anterior surface of the $\mathrm{C}-1$ lateral mass, behind the eustachian tubes. The parapharyngeal carotids are located behind, superior to, and lateral to the eustachian tubes, and the vertebral arteries are located behind and lateral to the eustachian tubes. Copyright Barrow Neurological Institute. Published with permission.

all transmucosal approaches, multiple clinical series have reported successful outcomes with other types of surgeries using implants. ${ }^{16,17,19,30,39}$ Administration of preoperative antibiotics is thought to be critical. Finally, avoiding injury to the VA is another important consideration. Preoperative images should be studied carefully to determine if there is a safe corridor for screw placement. The risk to the VA is lowest during the initial exposure and dissection, because it resides posterior to the lateral mass of $\mathrm{C}-1$. The risk is highest during cannulation of the pars interarticularis, because a trajectory placed too laterally could strike the VA where it traverses between the C-1 and C-2 lateral masses. In contrast to posterior approaches, where VA injury most often occurs in the sulcus arteriosus of $\mathrm{C}-1$, the anterior technique would not be expected to place the VA at risk in this location. In fact, most anomalous configurations of VA anatomy do not preclude anterior screw insertion. Usually these anatomical variations are consistently related to the posterior surface of the joint. ${ }^{33,38}$ If the VA is injured in the approach, angiography should be immediately obtained to confirm and address the injury.

\section{Conclusions}

This study demonstrates the feasibility of C1-2 transarticular screw placement through an expanded endoscopic endonasal approach following odontoidectomy. Radiological analysis of the anatomical detail demonstrated the optimal location of the screw entry point on C-1 and screw trajectory to capture the joint, and biomechanical assessment confirmed spinal rigid fixation similar to posteriorly placed transarticular screws. Key nuances of this technique include the use of customized angled instruments for screw placement, bilateral sphenoidectomy to improve surgical freedom, and image guidance. This technique may have certain unique advantages and disadvantages when compared with posterior $\mathrm{C} 1-2$ strategies in patients following odontoidectomy.

\section{Acknowledgments}

We thank Mr. Joseph Triano and Mr. Michael Marquard (NuVasive, San Diego) for providing the manual angled instruments for screw placement, and Mr. Bradford Burling for expert technical consultation on the StealthStation Treatment Guidance System (Medtronic).

\section{References}

1. Alfieri A, Jho HD, Cappabianca P, de Divitis E, Tschabitscher M: Endoscopic endonasal skull base surgery. Pituitary 3:40, 2000 (Abstract)

2. Alfieri A, Jho HD, Tschabitscher M: Endoscopic endonasal approach to the ventral cranio-cervical junction: anatomical study. Acta Neurochir (Wien) 144:219-225, 2002

3. Baird CJ, Conway JE, Sciubba DM, Prevedello DM, Quiñones-Hinojosa A, Kassam AB: Radiographic and anatomic basis of endoscopic anterior craniocervical decompression: a comparison of endonasal, transoral, and transcervical approaches. Neurosurgery 65 (6 Suppl):158-164, 2009

4. Carrabba G, Dehdashti AR, Gentili F: Surgery for clival lesions: open resection versus the expanded endoscopic endonasal approach. Neurosurg Focus 25(6):E7, 2008

5. Crawford NR, Brantley AG, Dickman CA, Koeneman EJ: An apparatus for applying pure nonconstraining moments to spine segments in vitro. Spine (Phila Pa 1976) 20:20972100,1995

6. Crawford NR, Dickman CA: Construction of local vertebral coordinate systems using a digitizing probe. Technical note. Spine (Phila Pa 1976) 22:559-563, 1997

7. Crawford NR, Hurlbert RJ, Choi WG, Dickman CA: Differential biomechanical effects of injury and wiring at C1-C2. Spine (Phila Pa 1976) 24:1894-1902, 1999

8. Crawford NR, Yamaguchi GT, Dickman CA: A new technique for determining 3-D joint angles: the tilt/twist method. Clin Biomech (Bristol, Avon) 14:153-165, 1999

9. Dasenbrock HH, Clarke MJ, Bydon A, Sciubba DM, Witham TF, Gokaslan ZL, et al: Endoscopic image-guided transcervical odontoidectomy: outcomes of 15 patients with basilar invagination. Neurosurgery 70:351-360, 2012

10. Dickman CA, Crawford NR, Brantley AG, Sonntag VKH: Biomechanical effects of transoral odontoidectomy. Neurosurgery 36:1146-1153, 1995

11. Dickman CA, Crawford NR, Paramore CG: Biomechanical characteristics of C1-2 cable fixations. J Neurosurg 85:316322, 1996

12. Dickman CA, Locantro J, Fessler RG: The influence of transoral odontoid resection on stability of the craniovertebral junction. J Neurosurg 77:525-530, 1992

13. Dickman CA, Spetzler RF, Sonntag VKH, Apostolides PJ: Transoral approach to the craniovertebral junction, in Dickman CA, Spetzler RF, Sonntag VKH (eds): Surgery of the Craniovertebral Junction. New York: Thieme, 1998, pp 355-369

14. Grob D, Crisco JJ III, Panjabi MM, Wang P, Dvorak J: Biomechanical evaluation of four different posterior atlantoaxial fixation techniques. Spine (Phila Pa 1976) 17:480-490, 1992

15. Harms J, Schmelzle R, Stoltze D: Osteosynthesen im occipto-cervicalen Übergang vom transoralen Zugang aus, in: XVII SICOT World Congress (eds): Abstract Book. Munich: Demeter Verlag, 1987, pp 32-33 (Abstract) 
16. Kandziora F, Mittlmeier T, Kerschbaumer F: Stage-related surgery for cervical spine instability in rheumatoid arthritis. Eur Spine J 8:371-381, 1999

17. Kandziora F, Schulze-Stahl N, Khodadadyan-Klostermann C, Schröder R, Mittlmeier T: Screw placement in transoral atlantoaxial plate systems: an anatomical study. J Neurosurg 95 (1 Suppl):80-87, 2001

18. Kassam AB, Snyderman C, Gardner P, Carrau R, Spiro R: The expanded endonasal approach: a fully endoscopic transnasal approach and resection of the odontoid process: technical case report. Neurosurgery 57:E213, 2005

19. Kerschbaumer F, Kandziora F, Klein C, Mittlmeier T, Starker M: Transoral decompression, anterior plate fixation, and posterior wire fusion for irreducible atlantoaxial kyphosis in rheumatoid arthritis. Spine (Phila Pa 1976) 25:2708-2715, 2000

20. Lall R, Patel NJ, Resnick DK: A review of complications associated with craniocervical fusion surgery. Neurosurgery 67:1396-1403, 2010

21. Lee KM, Yeom JS, Lee JO, Buchowski JM, Park KW, Chang BS, et al: Optimal trajectory for the atlantooccipital transarticular screw. Spine (Phila Pa 1976) 35:1562-1570, 2010

22. Lu DC, Roeser AC, Mummaneni VP, Mummaneni PV: Nuances of occipitocervical fixation. Neurosurgery 66 (3 Suppl):141-146, 2010

23. Melcher RP, Puttlitz CM, Kleinstueck FS, Lotz JC, Harms J, Bradford DS: Biomechanical testing of posterior atlantoaxial fixation techniques. Spine (Phila Pa 1976) 27:2435-2440, 2002

24. Messina A, Bruno MC, Decq P, Coste A, Cavallo LM, de Divittis E, et al: Pure endoscopic endonasal odontoidectomy: anatomical study. Neurosurg Rev 30:189-194, 2007

25. Naderi S, Crawford NR, Song GS, Sonntag VKH, Dickman $\mathrm{CA}$ : Biomechanical comparison of $\mathrm{C} 1-\mathrm{C} 2$ posterior fixations. Cable, graft, and screw combinations. Spine (Phila Pa 1976) 23:1946-1956, 1998

26. Nucci RC, Seigal S, Merola AA, Gorup J, Mroczek KJ, Dryer $\mathrm{J}$, et al: Computed tomographic evaluation of the normal adult odontoid. Implications for internal fixation. Spine (Phila Pa 1976) 20:264-270, 1995

27. Panjabi MM: Biomechanical evaluation of spinal fixation devices: I. A conceptual framework. Spine (Phila Pa 1976) 13:1129-1134, 1988

28. Panjabi MM, Krag M, Summers D, Videman T: Biomechanical time-tolerance of fresh cadaveric human spine specimens. J Orthop Res 3:292-300, 1985

29. Puttlitz CM, Goel VK, Clark CR, Traynelis VC, Scifert JL, Grosland NM: Biomechanical rationale for the pathology of rheumatoid arthritis in the craniovertebral junction. Spine (Phila Pa 1976) 25:1607-1616, 2000

30. Ruf M, Melcher R, Harms J: Transoral reduction and osteosynthesis $\mathrm{C} 1$ as a function-preserving option in the treatment of unstable Jefferson fractures. Spine (Phila Pa 1976) 29:823-827, 2004

31. Seker A, Inoue K, Osawa S, Akakin A, Kilic T, Rhoton AL Jr: Comparison of endoscopic transnasal and transoral approaches to the craniovertebral junction. World Neurosurg 74:583-602, 2010
32. Sinha S, Mirza S, Bishop N, Zaki H, McMullan J: Endoscopic endonasal resection of the odontoid peg for paediatric basilar invagination. Br J Neurosurg 26:487-489, 2012

33. Ulm AJ, Quiroga M, Russo A, Russo VM, Graziano F, Velasquez A, et al: Normal anatomical variations of the $V_{3}$ segment of the vertebral artery: surgical implications. J Neurosurg Spine 13:451-460, 2010

34. Vishteh AG, Crawford NR, Melton MS, Spetzler RF, Sonntag VKH, Dickman CA: Stability of the craniovertebral junction after unilateral occipital condyle resection: a biomechanical study. J Neurosurg 90 (1 Suppl):91-98, 1999

35. Weidner A, Wähler M, Chiu ST, Ullrich CG: Modification of C1-C2 transarticular screw fixation by image-guided surgery. Spine (Phila Pa 1976) 25:2668-2674, 2000

36. Wilke HJ, Fischer K, Kugler A, Magerl F, Claes L, Wörsdörfer O: In vitro investigations of internal fixation systems of the upper cervical spine. II. Stability of posterior atlantoaxial fixation techniques. Eur Spine J 1:191-199, 1992

37. Wu JC, Huang WC, Cheng H, Liang ML, Ho CY, Wong TT, et al: Endoscopic transnasal transclival odontoidectomy: a new approach to decompression: technical case report. Neurosurgery 63:ONSE92-ONSE94, 2008

38. Yamazaki M, Okawa A, Furuya T, Sakuma T, Takahashi H, Kato K, et al: Anomalous vertebral arteries in the extra- and intraosseous regions of the craniovertebral junction visualized by 3 -dimensional computed tomographic angiography: analysis of 100 consecutive surgical cases and review of the literature. Spine (Phila Pa 1976) 37:E1389-E1397, 2012

39. Yin Q, Ai F, Zhang K, Chang Y, Xia H, Wu Z, et al: Irreducible anterior atlantoaxial dislocation: one-stage treatment with a transoral atlantoaxial reduction plate fixation and fusion. Report of 5 cases and review of the literature. Spine (Phila Pa 1976) 30:E375-E381, 2005

40. Yu Y, Wang X, Zhang X, Hu F, Gu Y, Xie T, et al: Endoscopic transnasal odontoidectomy to treat basilar invagination with congenital osseous malformations. Eur Spine J 22:1127-1136, 2013

\section{Author Contributions}

Conception and design: Little, Mendes, Dickman, Crawford, Sonntag. Acquisition of data: Mendes, Rodriguez-Martinez, Kalb. Analysis and interpretation of data: Little, Mendes, Preul. Drafting the article: Little, Mendes. Critically revising the article: Little, Preul. Reviewed submitted version of manuscript: Little, Mendes, Dickman, Crawford, Sonntag. Statistical analysis: Mendes. Administrative/technical/material support: Preul. Study supervision: Crawford.

\section{Correspondence}

Andrew S. Little, c/o Neuroscience Publications, Barrow Neurological Institute, St. Joseph's Hospital and Medical Center, 350 W. Thomas Rd., Phoenix, AZ 85013.email: neuropub@ dignityhealth.org. 